\title{
Goals matter: Both achievement and pain-avoidance goals are associated with pain severity and disability in patients with low back and upper extremity pain
}

\author{
Petra A. Karsdorp ${ }^{\mathrm{a}, *}$, Johan W.S. Vlaeyen ${ }^{\mathrm{a}, \mathrm{b}}$ \\ ${ }^{a}$ Department Clinical Psychological Science, Research Group Behavioral Medicine, Maastricht University, PO Box 616, 6200 MD Maastricht, The Netherlands \\ ${ }^{\mathrm{b}}$ Department of Psychology, Research Group Health Psychology, University of Leuven, Tiensestraat 102, 3000 Leuven, Belgium
}

Sponsorships or competing interests that may be relevant to content are disclosed at the end of this article.

\section{A R T I C L E I N F O}

\section{Article history:}

Received 21 July 2010

Received in revised form 31 January 2011

Accepted 7 February 2011

\section{Keywords:}

Achievement goals

Disability

Goal pursuit

Motivation

Pain

Pain-avoidance goals

\begin{abstract}
A B S T R A C T
It has been proposed that goal pursuit plays a role in the development of chronic pain disorders. On the basis of (affective) motivational theories, it was hypothesized that both long-term achievement goals and short-term hedonic goals would be related to increased levels of pain and disability, particularly in patients with high negative affect. Participants with musculoskeletal pain complaints $(N=299)$ completed a battery of questionnaires including a novel goal pursuit questionnaire (GPQ) measuring the extent to which participants preferred hedonic goals (mood-management or pain-avoidance goals) over achievement goals in various situations. Explorative factor analysis of the GPQ resulted in a reliable painavoidance $(\alpha=.88)$ and mood-management subscale $(\alpha=.76)$. A nonlinear, U-shaped relationship was found among the pain-avoidance scale (but not the mood-management scale) and pain and disability. This indicated that participants who strongly endorsed either achievement or pain-avoidance goals also reported higher pain and disability levels while controlling for biographical variables and pain catastrophizing. For pain but not disability, these relationships were only found among patients with high negative affect. For disability, goal pursuit and negative affect were independently related to disability. These findings provide support for the validity of an affective-motivational approach to chronic pain, suggesting that the experience of pain and the interference of pain on daily life activities depends on goal pursuit and negative affect. Interventions aimed at improving disability in chronic pain should address both patient's goal pursuit and negative affect.
\end{abstract}

Crown Copyright $\odot 2011$ Published by Elsevier B.V. on behalf of International Association for the Study of Pain. All rights reserved.

\section{Introduction}

Pain symptoms are the most common health problems among the working population [36]. The prevalence of low back pain and neck/upper extremity pain within the past 12 months varies from $35 \%$ to $52 \%[55,20]$ and $35 \%$ to $56 \%$, respectively, in a working population $[29,55,20]$. It has been suggested that either excessive avoidance [63] or persistence behavior may precede disability in low back pain and neck/upper extremity pain $[2,5,21,23,32$, $52,59]$. However, the mechanisms explaining these behavior patterns are largely unknown.

Prevailing fear-avoidance models postulate that pain-related fear predicts avoidance of painful activities [3,9,63]. However, fear-avoidance models have been criticized recently because first, they do not explain excessive task persistence in chronic pain [64], and second, they do not take into account that pain is often experienced in a context of goal pursuit [56]. An individual with

\footnotetext{
* Corresponding author. Tel.: +31 43 3881249; fax: +31 433884155 .

E-mail address: P.Karsdorp@maastrichtuniversity.nl.edu (P.A. Karsdorp).
}

chronic wrist pain who is typing a report may experience a goal conflict between a short-term hedonic goal to minimize pain and a long-term achievement goal to finish the report. Strong achievement goals may diminish the tendency to avoid painful activities. In line with this motivational perspective, it has been demonstrated that achievement goals as opposed to hedonic goals enhance task persistence during a painful weight lifting task in patients with work-related upper extremity pain above and beyond the effect of pain-related fear [24].

Affective-motivational models have been proposed as well, such as the Mood-as-Input model (MAI) [35,64], which postulates that the motivational effect of goal pursuit on behavior is moderated by mood. The MAI model differentiates between 2 goals that may have opposing effects on behavior dependent on mood: shortterm hedonic goals and long-term achievement goals. According to the MAI model, negative moods signal individuals with achievement goals that they have not dealt with the task satisfactorily, leading to task persistence, whereas negative moods signal individuals with hedonic goals that they are no longer enjoying the task anymore, leading to task avoidance. Given that both avoidance 
and persistence behavior is detrimental for the development of chronic pain disorders, a habitual tendency to adopt either hedonic or achievement goals may lead to more disability and pain, particularly when patients experience negative affect [64].

The aim of the present study was first to test whether hedonic and achievement goals are related to pain severity and disability in individuals reporting pain, and second to test whether these relationships are moderated by negative affect. A goal pursuit questionnaire (GPQ) was developed to measure a patient's preference for hedonic goals relative to achievement goals. It was predicted that a strong endorsement of achievement or hedonic goals would be related to greater pain and disability specifically in individuals reporting high negative affectivity.

\section{Methods}

\subsection{Participants}

The participants were recruited via newspaper advertisements and Internet sites. Individuals experiencing pain in the lower back, neck, shoulder, upper arm, forearm, elbow, wrist, or hand were invited to participate in the study and to complete a series of questionnaires online or with paper and pencil. The inclusion criteria required participants to be between 18 and 65 years old and experiencing pain symptoms in at least one of the above-mentioned body sites. People with insufficient knowledge of the Dutch language were excluded. The Medical Ethics Committee of Maastricht University approved the research protocol.

\subsection{Biographical and medical questions}

A questionnaire was used to measure participants biographical and medical data, such as age, gender, level of education, marital status, number of children, job status, number of years since first pain complaints, duration of present pain period, diagnosis made by a physician, surgery of the painful body part, pain treatment, and use of pain medication.

\subsection{Goal pursuit}

To assess a participant's habitual goal pursuit, a 24-item GPQ was developed. The items were drafted by the authors on the basis of the MAI model. The items were construed such that they measured the 2 MAI goals, hedonic and achievement goals, postulated to have opposing effects on behavior dependent on mood. Because both goals could be activated within one person at the same time, the items were formulated such that people had to rate the strength of one goal relative to the other goal. In this way it was possible to measure the particular goal that was likely to influence behavior. Fourteen experts in the field of pain research and goal pursuit, and 5 patients with chronic pain disorder provided comments on a preliminary version of the questionnaire regarding the comprehensibility of the items and the applicability of the items to daily life situations. Each item comprised a description of a daily situation in which hedonic goals conflict with achievement goals. The GPQ included 24 vignettes belonging to 1 of 3 categories: a painful situation (8 items), an unpleasant nonpainful situation ( 8 items), and a pleasant nonpainful situation ( 8 items). The items on painful situations measured a person's preference for pain-avoidance goals relative to achievement goals. The items on nonpainful pleasant and unpleasant situations measured a person's preference for mood-management goals (ie, maintaining a positive mood) [14] relative to achievement goals. Typical examples are: "While typing a report, your neck becomes increasingly painful. Your boss expects the report to be finished that day" (pain- ful situation), "You are participating in a course and will have to take an exam tomorrow. You find the textbooks boring and you are having trouble learning the subject matter" (unpleasant nonpainful situation), and "You have received some funny e-mail messages. Since you want to reply to the messages, there is less and less time available to prepare a presentation. You are expected to finish the presentation today" (pleasant nonpainful situation). Within each category, half of the situations were related to work and the other half were related to leisure time and study. Participants were asked to imagine as vividly as possible that the situation was happening to them now, and how they would judge that situation. After each situation, a thought was presented. Each thought was about a person's preference for hedonic goals as opposed to achievement goals. An example of such a thought was: "I think it is more important for me to reduce dullness now, than for me to do well at the exam." For the pain-related vignettes, the judgment was about a person's preference for pain-avoidance goals as opposed to achievement goals. An example of a painrelated thought was: "I think it is more important for the pain in my neck to be reduced now, than for my report to be finished on time." Participants were asked to what extent they agreed with this thought on a 6-point Likert scale ranging from 1 (strongly disagree) to 6 (strongly agree). Note that participants were explicitly instructed that this thought was not about what a person would do in the situation described, but what a person would think. Higher mean scores reflect stronger preferences for hedonic goals relative to achievement goals.

\subsection{Negative affectivity}

Trait negative affect was measured to test its effect on disability and pain with the trait version of the Positive and Negative Affect Schedule (PANAS-Trait) [66,25]. The PANAS consists of 20 affective words, 10 positive (eg, enthusiastic, active, proud) and 10 negative (eg, irritable, frightened, ashamed). Only the 10 negative items were used for the analysis in the present study. Participants are instructed to rate the extent to which they generally feel or experience each of the emotions (trait). Each item is rated on a 5-point Likert scale ranging from 1 (very slightly or not at all) to 5 (extremely). High mean total scores on the negative affectivity subscale indicate high trait negative affectivity. Convergent and discriminant validity of the Dutch version is satisfactory [16]. In the present study, the internal consistency was adequate (Cronbach's $\alpha=.88$ ).

\subsection{Pain symptoms}

Anatomical region and side (left or right) of the pain and discomfort was gathered by means of a validated modified version [18] of the Nordic Questionnaire [26]. The anatomical regions were: neck, shoulder (left or right), upper back, low back, elbow (left or right), wrist/hand (left or right), hip (left or right), knee (left or right), and ankle/feet (left or right). To measure pain severity in each region, the 2-item Pain Severity subscale of the Dutch version of the Multidimensional Pain Inventory was used (MPI) [28]. The 2 items are: "Rate the level of your pain at the present moment" and "On average, how severe has your pain been during the last week." The items are answered on a 7-point Likert scale ranging from 0 (no pain) to 6 (the worst pain imaginable). The MPI has been shown to have good reliability and validity [28]. A total mean pain score was calculated by averaging the pain scores for the different anatomical regions. In the present study, the internal consistency was adequate for the pain scores of the different anatomical regions separately (Cronbach's $\alpha$ ranging from .88 to .95) and for the total pain score (Cronbach's $\alpha=.93$ ). 


\subsection{Pain-related disability}

The Dutch version of the Pain Disability Index (PDI) [40] was used to measure pain-related disability. The PDI is a 7-item scale measuring the degree of disability people experience in each of 7 different life domains: family/home responsibilities, recreation, social activity, occupation, sexual behavior, self-care, and life supporting activities. Ratings are made on an 11-point scale ranging from 0 (no disability) to 10 (total disability). High mean total scores indicate high disability. The PDI has been shown to have good reliability and validity $[48,54]$. In the present study, the internal consistency was adequate (Cronbach's $\alpha=.86$ ).

\subsection{Pain catastrophizing}

The Dutch version of the Pain Catastrophizing Scale (PCS) $[51,57]$ was used to establish the construct validity of the GPQ and to test whether high pain catastrophizing would be related to a greater endorsement of hedonic goals. Given that pain catastrophizing is associated with the persistent search for a solution for pain $[1,13]$, we expected the association with the items measuring pain avoidance goals to be stronger than with the items measuring mood-management goals. The PCS is a 13-item questionnaire that assesses catastrophic thinking in response to pain. The questionnaire consists of 3 subscales: helplessness, magnification, and rumination. The PCS total score, which was used in the present research, offers a good index of the pain catastrophizing construct, because the 3 subscales are highly correlated. An example of an item is: "I become afraid that the pain will get worse." Psychometric properties of the Dutch version of the PCS are satisfactory [9,58,62]. Ratings are made on a 5-point scale ranging from 0 (not at all) to 4 (always). High mean total scores indicate high pain catastrophizing. In the present study, the internal consistency was adequate (Cronbach's $\alpha=.90$ ).

\subsection{Sense of responsibility}

Research has demonstrated that an inflated sense of responsibility is associated with achievement goals [49]. To establish the construct validity of the GPQ and to determine whether endorsement of achievement goals is associated with a higher sense of responsibility, the Dutch translation of the 26-item Responsibility Attitude Scale (RAS) was used [41]. The RAS measures sense of responsibility (eg, "I often feel responsible for things which go wrong"). Respondents are required to indicate the degree to which they agree with each statement, based on a 7-point scale ranging from 1 (totally disagree) to 7 (totally agree). Higher mean total scores on the questionnaire represent higher levels of perceived responsibility. The English version of the RAS has been shown to have high test-retest reliability [41] and high internal consistency $[39,41]$. For the purpose of the present study, a Dutch version was used after translation into Dutch by the authors, and backtranslation into English by a professional translator. This version was subsequently checked and approved by the original author of the RAS (Paul Salkovskis). In the present study, the internal consistency of the RAS-DV was adequate (Cronbach's $\alpha=.92$ ).

\subsection{Perfectionism}

To establish the construct validity of the GPQ and to determine whether endorsement of achievement goals is associated with a higher degree of perfectionism, a Dutch version of the Multidimensional Perfectionism Scale (MPS) [15] was used. The questionnaire measures neurotic perfectionism and consists of 35 items and 5 subscales: concerns over mistakes, personal standards, parental expectations, parental criticism, doubt about expectations. Re- sponse categories vary from 1 to 5 . An example of an item is: "I set higher goals than most people." Higher mean total scores indicate higher neurotic perfectionism [60]. In the present, study the internal consistency was adequate (Cronbach's $\alpha=.93$ ).

\subsection{Conscientiousness}

People low on conscientiousness typically show low levels of impulsive control [8] and therefore may be more inclined to adopt hedonic goals. To establish the construct validity of the GPQ and to determine whether endorsement of hedonic goals is associated with low levels of conscientiousness, the 12-item conscientiousness subscale of the Dutch version of the Neuroticism, Extraversion, Openness to New Experience-Five Factor Inventory (NEO-FFI) [8] was used. Each item is scored on a 5-point Likert scale ranging from 1 (strongly disagree) to 4 (strongly agree). Higher mean total scores represent higher conscientiousness. An example of an item is: "I work hard to reach my goals." There is considerable evidence for the reliability and construct validity of the Dutch version of the NEO-FFI [19]. In the present study, the internal consistency was adequate (Cronbach's $\alpha=.81$ ).

\subsection{Fear of negative evaluations}

To establish the construct validity of the GPQ and to determine whether endorsement of achievement goals is associated with high fear of negative evaluations a Dutch translation of the Brief Fear of Negative Evaluation Scale version II (BFNE-II) [6] was used. The BFNE-II comprises 12 items, each rated on a 5-point Likert scale ranging from 0 (not at all characteristic of me) to 4 (extremely characteristic of me). An example of an item is: "I am afraid that others will not approve of me." High mean total scores indicate high fear of negative evaluations. Both the English and Dutch versions of the BFNE-II has shown to be satisfactory with respect to reliability and validity [6,61]. In the present, study the internal consistency was adequate (Cronbach's $\alpha=.97$ ).

\subsection{Statistical analysis}

Principal component analysis with oblique rotation was performed with SPSS 15.0 (SPSS, Chicago, IL) to explore the factor structure of the GPQ. The number of factors extracted was determined on the basis of the scree plot and eigenvalues greater than 1. To test the construct validity of the subscales, Pearson's product-moment correlation coefficients were calculated between the GPQ and PANAS, PCS, RAS, MPS, NEO-FFI, and BFNE-II.

To test whether the relationship between negative affectivity on the one hand and pain and pain-related disability on the other was moderated by the square of the GPQ subscales beyond demographic variables and pain catastrophizing 2 hierarchical regression analyses were conducted with pain or pain-related disability as dependent variables. At the first step, gender, age, education, pain duration, and pain catastrophizing were entered. At the second step, the centered variables negative affectivity, and the goal pursuit subscales of the GPQ were entered. At the third step, the interactions between the GPQ subscales and the negative affect scale were entered. At the fourth step, the square of the GPQ subscales were entered. At the final step, the 3-way interactions between negative affectivity and the square of the GPQ subscales were entered.

\section{Results}

\subsection{Participants}

Three hundred one participants with pain complaints in the upper extremities, neck, or low back were accepted to participate 
and completed the questionnaires. Two participants were excluded from the analysis because they completed only 4 or fewer of the 15 questionnaires, leaving 299 participants in the study. Demographic data of the sample are presented in Table 1.

The data set of the study contained 641 missing data $(0.6 \%)$ in 39 participants (12.4\%). These nonmonotone missing data were imputed by a modification of the regression method (ie, predicting the values of the missing data from other variables in the data set) by adding an error term known as data augmentation and imputation. Data imputation was performed with the statistical software package NORM version 2.02 [44].

\subsection{Explorative factor analysis}

Principal component analysis with oblique rotation was performed on 24 items of the GPQ for a sample of 299 participants. The Kaiser-Meyer-Olkin (KMO) Measure of Sampling Adequacy was .89 , indicating that the items were appropriate for principal component analysis [53]. On the basis of the scree plot, 2 factors were extracted with eigenvalues greater than 1 . Together, these factors accounted for $42.78 \%$ of the total variance of the original items, with the first factor explaining $32.09 \%$ of the variance and the second factor explaining $10.68 \%$ of the variance. Loadings of variables on factors, communalities, and percentages of variance and covariance are shown in Table 2 . Inspection of the oblique rotated solution showed that factor I mainly consisted of items related to pain and factor II of items not related to pain. Loadings of 5 items did not exceed .40 on either factor 1 or 2 , and one item loaded highly on both factor 1 (.40) and factor 2 (.41). Therefore, these 6 items were excluded (items 8, 9, 10, 17, 20, 22). Moreover, 2 items measuring the importance of performance goals vs the goal to diminish exhaustion (item 15) and stress (item 16) loaded highly on the pain-related factor I. These 2 items were excluded in order to construct a pain-related subscale consisting of only pain items. A second principal component analysis without these 8 items revealed a 2 -factor solution with eigenvalues exceeding 1 . Together, these factors accounted for $48.48 \%$ of the total variance, with factor I accounting for $33.02 \%$ of the variance and factor II for $15.46 \%$. Inspection of the oblique rotated solution showed that factor I was created by 8 vignettes regarding the choice between an achievement goal and a pain-avoidance goal $(1,3,6,7,14,18$, $21,24)$, with higher scores reflecting stronger preferences for pain-avoidance goals relative to achievement goals. Factor I was labeled as pain-avoidance goal. Factor II comprised 8 vignettes that were non-pain related $(2,4,5,11,12,13,19,23)$, with higher scores reflecting stronger preferences for mood-management goals relative to achievement goals. This factor was labeled as moodmanagement goal. The Cronbach's $\alpha$ values of the pain-avoidance goal and mood-management goal subscales were .88 and .76, respectively. The Pearson's product-moment correlation between both scales was moderate, with $r(299)=.37$ and $P<.001$, suggesting that the pain-avoidance and mood-management subscales measure related but distinct constructs.

\subsection{Construct validity}

Means, SDs, and Pearson's product-moment correlation coefficients among the pain-avoidance goal, mood-management goal subscales of the GPQ with negative affectivity, pain catastrophizing, sense of responsibility, perfectionism, conscientiousness, and fear of negative evaluation are presented in Table 3. Participants who showed a stronger tendency to endorse pain-avoidance goals relative to achievement goals were less perfectionistic, had a lower sense of responsibility and experienced less fear of negative evaluations (all $P$ values <.05). In addition, participants who showed a stronger tendency to endorse mood-management goals
Table 1

Demographic characteristics of the patient sample.

\begin{tabular}{|c|c|}
\hline Characteristic & Value \\
\hline \multicolumn{2}{|l|}{ Age, $y$} \\
\hline Mean (SD) & $\begin{array}{l}41.08 \\
(12.71)\end{array}$ \\
\hline Range & $18-64$ \\
\hline Male sex & $18.1 \%$ \\
\hline $\begin{array}{l}\text { Level of education }^{a} \\
\text { Mean (SD) } \\
\text { Range } \\
\text { Primary education } \\
\text { Secondary education } \\
\text { Intermediate vocational education } \\
\text { Higher vocational education } \\
\text { Higher general education }\end{array}$ & $\begin{array}{l}3.03(1.05) \\
1-5 \\
2.3 \% \\
36.1 \% \\
26.8 \% \\
25.1 \% \\
9.7 \%\end{array}$ \\
\hline $\begin{array}{l}\text { Marital status } \\
\text { Married } \\
\text { Unmarried, living together } \\
\text { Relationship, living apart } \\
\text { Single } \\
\text { Divorced } \\
\text { Widowed } \\
\text { Unmarried, living with parents }\end{array}$ & \begin{tabular}{l|l}
$42.8 \%$ \\
$21.4 \%$ \\
$4.7 \%$ \\
$15.7 \%$ \\
$8.0 \%$ \\
$1.3 \%$ \\
$6.0 \%$
\end{tabular} \\
\hline $\begin{array}{l}\text { Number of children } \\
\text { Mean (SD) } \\
\text { Range }\end{array}$ & $\begin{array}{l}1.11(1.36) \\
1-9\end{array}$ \\
\hline $\begin{array}{l}\text { Job } \\
\text { Working } \\
\text { Retired } \\
100 \% \text { disability pension } \\
\text { Partial disability pension }\end{array}$ & $\begin{array}{l}63.2 \% \\
3.7 \% \\
6.0 \% \\
38.5 \%\end{array}$ \\
\hline $\begin{array}{l}\text { Number of years since first pain complaints } \\
\text { Mean (SD) } \\
\text { Range }\end{array}$ & $\begin{array}{l}9.19(9.13) \\
0-52\end{array}$ \\
\hline $\begin{array}{l}\text { Duration of present pain period }(y) \\
\text { Mean (SD) } \\
\text { Range }\end{array}$ & $\begin{array}{l}6.21(7.97) \\
0.01-37\end{array}$ \\
\hline $\begin{array}{l}\text { Diagnosis made by a physician (according to the patient) } \\
\text { Upper extremity pain } \\
\text { Fibromyalgia } \\
\text { Rheumatic disorder } \\
\text { Back pain } \\
\text { Combination } 1-4 \\
\text { Other (cancer, whiplash, hypermobility, chronic fatigue } \\
\text { syndrome) } \\
\text { No diagnosis }\end{array}$ & $\begin{array}{l}16.4 \% \\
17.1 \% \\
7.9 \% \\
18.1 \% \\
10.3 \% \\
4.8 \% \\
\\
25.3 \%\end{array}$ \\
\hline $\begin{array}{l}\text { Site of pain } \\
\text { Upper extremity pain } \\
\text { Back pain } \\
\text { Upper extremity and back pain } \\
\text { Upper and lower extremity pain } \\
\text { Back and lower extremity pain } \\
\text { Upper and lower extremity and back pain }\end{array}$ & \begin{tabular}{l|}
$13.4 \%$ \\
$3.7 \%$ \\
$17.1 \%$ \\
$8.0 \%$ \\
$5.7 \%$ \\
$52.2 \%$
\end{tabular} \\
\hline Surgery performed on the painful body part & $24.7 \%$ \\
\hline $\begin{array}{l}\text { Treatment for pain } \\
\text { Physician } \\
\text { Psychologist/psychiatrist } \\
\text { Physiotherapist }\end{array}$ & $\begin{array}{l}34.8 \% \\
4.0 \% \\
45.8 \%\end{array}$ \\
\hline Use of pain medication & $52.8 \%$ \\
\hline
\end{tabular}

a Level of education is based on the Dutch educational system ranging from primary school (score 1 ) to higher general education (5). Score 3 refers to intermediate vocational education.

relative to achievement goals were less conscientious and catastrophized more about pain (all $P$ values $<.05$ ). Finally, patients high on negative affect showed a lower endorsement of pain-avoidance goals $(P<.05)$. No other significant associations were found between pain-avoidance and mood-management goals and the other measures (all $P$ values $>.05$ ). 
Table 2

Factor loadings of the GPQ.

\begin{tabular}{|c|c|c|c|c|c|}
\hline Item & I think it is more important... & Factor I & Factor II & Mean & SD \\
\hline 6 & ...for the pain in my upper back to be reduced now, than for the boxes to be moved outside & .84 & & 4.13 & 1.61 \\
\hline 14 & ...for the pain in my wrists to be reduced now, than for the album to be completed & .80 & & 4.12 & 1.56 \\
\hline 21 & ...for the pain in my forearm to be reduced now, than for the car to be repaired & .80 & & 3.79 & 1.47 \\
\hline 3 & ...for the pain in my shoulder to be reduced now, than for the paintwork to be completed. & .78 & & 3.71 & 1.56 \\
\hline 18 & ...for the pain in my hands to be reduced now, than to rehearse the compositions & .75 & & 4.10 & 1.52 \\
\hline 7 & ...for the pain in my back to be reduced now, than for the house to be clean & .75 & & 4.33 & 1.54 \\
\hline 24 & ...for the pain in my elbow to be reduced now, than for the meeting to be arranged & .63 & & 2.91 & 1.46 \\
\hline 1 & ...for the pain in my neck to be reduced now, than for my report to be finished on time & .61 & & 3.15 & 1.64 \\
\hline 13 & ...to write a nice e-mail reply than to finish the presentation & & .76 & 1.96 & 1.19 \\
\hline 4 & ...to read the exciting book now than to write a good report & & .73 & 1.85 & 1.16 \\
\hline 2 & ...to tell my holiday stories than to finish my work & & .68 & 1.79 & 1.05 \\
\hline 11 & ...for me to reduce dullness, than for me to do well at the exam & & .60 & 2.19 & 1.33 \\
\hline 19 & ...for me to have interesting conversations now, than to have the decisions made & & .60 & 2.56 & 1.23 \\
\hline 12 & ...for me to decrease my boredom, than for me to finish the assembly line work & & .51 & 2.40 & 1.37 \\
\hline 23 & ...for me to enjoy my work now, than to finish the other obligations & & .49 & 2.96 & 1.28 \\
\hline 5 & ...for me to for me to prevent despair now, than to succeed in obtaining a correct calculation & & .46 & 2.88 & 1.57 \\
\hline
\end{tabular}

\subsection{Regression analyses}

Pain severity. To test whether the pain-avoidance and the moodmanagement goal subscales of the GPQ in combination with negative affectivity were related to pain symptoms, a hierarchical regression analysis was conducted (Table 4). At step 1, age, gender, educational level, pain duration, and the PCS explained a significant amount of variance in pain, with $R^{2}=.18, F(5,293)=12.72$, $P<.001$. Being female, possessing a higher level of education, having a longer duration of pain complaints, and having higher PCS scores were associated with higher levels of pain severity $(P<.05)$. At step 2 , the centered main effects of negative affect, and the pain-avoidance and mood-management goal subscales explained a significant additional amount of variance in pain, with $\Delta R^{2}=.04, F(3,290)=4.72, P<.01$. Negative affect was the only contributor to the variance explained, indicating that patients with more negative affect also reported more pain symptoms $(P<.05)$. At step 3, the interaction terms, pain-avoidance goal $\times$ negative affect, and mood-management goal $\times$ negative affect, did not significantly explain any additional variance in pain symptoms, with $\Delta R^{2}<.01, F(2,288)=0.56, P=.57$. At step 4 , the quadratic terms of the pain-avoidance and mood-management-goal scales explained a significant additional amount of variance in pain, with $\Delta R^{2}=.03, F(2,286)=5.15, P<.01$. However, the effects of the square of the pain-avoidance goal and mood-management goal did not reach statistical significance (all $P$ values $>.05$ ). At step 5 , the interactions between negative affect and either the square of the pain-avoidance goal or mood-management goal predicted a significant additional amount of variance, with $\Delta R^{2}=.02$, $F(2,284)=4.53, P=.01$, which was due to the significant negative affect $\times(\text { pain-avoidance goal })^{2}$ interaction $(P<.05)$. Individuals scoring high on negative affectivity experience more pain symptoms the greater their tendency to endorse either achievement or pain-avoidance goals (Fig. 1). For individuals scoring low on negative affectivity, no U-shaped association was observed.

Pain-related disability. To test whether both GPQ subscales in combination with negative affectivity were related to pain-related disability, a similar hierarchical regression analysis was conducted (Table 4). At step 1, age, gender, educational level, pain duration and the PCS explained a significant amount of variance in disability, with $R^{2}=.21, F(5,293)=15.10, P<.001$. Being female and possessing a higher level of education, longer duration of pain complaints, and higher PCS scores were associated with higher disability levels $(P<.05)$. At step 2 , the centered main effects of negative affect and the pain-avoidance and mood-management goal subscales explained a significant additional amount of variance in pain-related disability, with $\Delta R^{2}=.04, F(3,290)=5.01, P=.002$. Negative affect was the only contributor to the variance explained, indicating that patients with more negative affect also reported more pain-related disability $(P<.05)$. At step 3 , the interaction terms, pain-avoidance goal $\times$ negative affect and mood-management goal $\times$ negative affect, did not significantly explain an additional amount of variance in disability, with $\Delta R^{2}=.01$, $F(2,288)=1.00, P=.37$. At step 4 , the quadratic terms of the painavoidance and mood-management goal subscales explained a significant additional amount of variance in disability, with $\Delta R^{2}=.02$,

Table 3

Means, SDs, and Pearson's correlations between the mood-management and pain-avoidance goals and other measures.

\begin{tabular}{|c|c|c|c|}
\hline Measure & Mean (SD) & Pain-avoidance goal & Mood-management goal \\
\hline Pain-avoidance goal (GPQ) & $3.80(1.15)$ & - & - \\
\hline Mood-management goal (GPQ) & $2.35(0.81)$ & $.37^{* * *}$ & - \\
\hline Negative affectivity (NA) & $2.04(0.74)$ & $-.18^{* *}$ & .04 \\
\hline Pain catastrophizing (PCS) & $1.53(0.76)$ & -.02 & $.12^{*}$ \\
\hline Responsibility (RAS) & $4.15(0.93)$ & $-.30^{* * * *}$ & .06 \\
\hline Perfectionism (MPS) & $2.66(0.66)$ & $-.21^{* * *}$ & -.05 \\
\hline Conscientiousness (NEO-FFI-C) & $3.80(0.54)$ & -.09 & $-.25^{* * *}$ \\
\hline Fear of negative evaluations (BFNE-II) & $2.86(1.11)$ & $-.24^{* * *}$ & -.05 \\
\hline Pain severity & $1.21(0.92)$ & -.10 & .03 \\
\hline Disability (PDI) & $4.00(2.06)$ & .03 & .06 \\
\hline
\end{tabular}

NA, Negative Affectivity Scale; PCS, Pain Catastrophizing Scale; RAS, Responsibility Attitude Scale; MPS, Multidimensional Perfectionism Scale; NEO-FFI-C, Conscientiousness Scale of the Neuroticism, Extraversion, Openness to New Experience-Five Factor Inventory; BFNE-II, Brief Fear of Negative Evaluation Scale; PDI, Pain Disability Index. * $P<.05$.

${ }^{* *} P<.01$.

*** $P<.001$ 
Table 4

Hierarchical multiple regression analysis with pain and disability as dependent variables.

\begin{tabular}{|c|c|c|c|c|c|}
\hline \multirow[t]{2}{*}{ Step } & \multirow[t]{2}{*}{ Predictor } & \multicolumn{2}{|l|}{ Pain } & \multicolumn{2}{|l|}{ Disability } \\
\hline & & $\mathrm{B}(\mathrm{SE})^{\mathrm{a}}$ & $\Delta R^{2}$ & $\mathrm{~B}(\mathrm{SE})^{\mathrm{a}}$ & $\Delta R^{2}$ \\
\hline \multirow[t]{6}{*}{1} & & & $.18^{* * *}$ & & $.21^{* * *}$ \\
\hline & Sex & $\begin{array}{l}.47 \\
(.13)^{* * * *}\end{array}$ & & $.58(.28)^{*}$ & \\
\hline & Age & $.01(.01)^{*}$ & & $.02(.01)^{*}$ & \\
\hline & Education & $\begin{array}{l}-.10 \\
(.05)^{*}\end{array}$ & & $\begin{array}{l}-.30 \\
(.10)^{* *}\end{array}$ & \\
\hline & Pain duration & $\begin{array}{l}.02 \\
(.01)^{* * *}\end{array}$ & & $.04(.01)^{* *}$ & \\
\hline & Pain catastrophizing & $.14(.07)$ & & $\begin{array}{l}.63 \\
(.16)^{* * *}\end{array}$ & \\
\hline \multirow[t]{4}{*}{2} & & & $.04^{* *}$ & & $.04^{* *}$ \\
\hline & NA & $.05(.09)$ & & $.67(.21)^{* *}$ & \\
\hline & Pain-avoidance goal & $\begin{array}{l}<-.01 \\
(.05)\end{array}$ & & $.21(.10)^{*}$ & \\
\hline & Mood-management goal & $.03(.08)$ & & $.08(.17)$ & \\
\hline \multirow[t]{3}{*}{3} & & & $<.01$ & & .01 \\
\hline & NA $\times$ Pain-avoidance goal & $.06(.06)$ & & $.22(.14)$ & \\
\hline & $\begin{array}{l}\text { NA } \times \text { Mood-management } \\
\text { goal }\end{array}$ & $\begin{array}{l}-.02 \\
(.10)\end{array}$ & & $.43(.22)$ & \\
\hline \multirow[t]{3}{*}{4} & & & $.03^{* *}$ & & $.02^{*}$ \\
\hline & ${\text { (Pain-avoidance goal })^{2}}^{2}$ & $.05(.03)$ & & $.22(.07)^{* * *}$ & \\
\hline & (Mood-management goal) $^{2}$ & $.08(.05)$ & & $-.04(.12)$ & \\
\hline \multirow[t]{3}{*}{5} & & & $.02^{*}$ & & .01 \\
\hline & $\mathrm{NA} \times(\text { Pain-avoidance goal })^{2}$ & $\begin{array}{l}.11 \\
(.04)^{* * *}\end{array}$ & & $.12(.09)$ & \\
\hline & $\begin{array}{l}\mathrm{NA} \times(\text { Mood-management } \\
\text { goal })^{2}\end{array}$ & $\begin{array}{l}<-.01 \\
(.07)\end{array}$ & & $-.29(.15)$ & \\
\hline
\end{tabular}

\footnotetext{
a Regression coefficients are from the complete regression model. NA, negative affectivity.

${ }^{*} P<.05$.

** $P<.01$.

${ }^{* * *} P<.001$.
}

$F(2,286)=4.65, P=.01$. The square of the pain-avoidance goal subscale was the only significant contributor to the variance explained, indicating that individuals endorsing either an achievement or pain-avoidance goal reported more disability $(P<.05)$. At step 5 , the interactions of negative affect with either the square of pain-avoidance or mood-management goal subscales did not predict a significant additional amount of variance, with $\Delta R^{2}=.01, F(2,284)=2.00, P=.14$. Fig. 2 plays the U-shaped association between goals and pain-related disability. Note that for all regression analyses, the variance inflation factors were lower than 10 (range 1.07-3.41), showing that there was no problem of multicollinearity (Figs. 1 and 2).

\section{Discussion}

The aim of the present study was to test whether a strong endorsement of either achievement goals or hedonic (moodmanagement or pain avoidance) goals is related to pain severity and pain-related disability in individuals reporting pain, and whether these relationships are moderated by negative affect. For this purpose, a GPQ was developed that measures a patient's goal preferences. Explorative factor analysis yielded 2 subscales each consisting of 8 items, one measuring a person's preference for mood-management goals relative to achievement goals (mood-management subscale) and the other measuring a person's preference for pain-avoidance goals relative to achievement goals (pain-avoidance subscale). The internal reliability of both scales was adequate. Additionally, the findings that the GPQ was associated with questionnaires measuring achievement- or hedonic-related constructs supported the construct validity of the GPQ. As expected, a stronger preference for achievement goals relative to pain-avoidance goals was related to a higher sense of responsibility, perfectionism, and fear of negative evaluations. Moreover, a stronger preference for mood-management goals relative to achievement goals was related to a stronger tendency to catastrophize about pain and lower conscientiousness (less impulsive control) [8]. These findings corroborate previous research demonstrating an association between inflated sense of responsibility and achievement goals [49] and between pain catastrophizing and the hedonic goal to find a solution for pain [1,13]. Note that although the relationship between the GPQ and other measures was in the predicted direction, overall the effect sizes were small to moderate. Moreover, some of the predicted relationships did not reach statistical significance, eg, among the mood-management subscale and the responsibility, perfectionism and fear of negative evaluations questionnaires. Similarly, the associations among the pain-avoidance goal subscale and the pain catastrophizing and conscientiousness scales was nonsignificant, indicating that the construct measured by the GPQ is distinct from the constructs measured by other related questionnaires. The GPQ measures the relative strength between the hedonic (moodmanagement or pain avoidance) and achievement goals, whereas the other questionnaires measure only the strength of one of these goals separately. For example, it is possible that patients showing a stronger endorsement of achievement goals relative to pain-avoidance goals may still overall show a strong tendency to pursue painavoidance goals relative to the other patients. This may have reduced the correlations between the GPQ and the other measures, such as the PCS. In sum, and taking into account the different questioning format of the GPQ as compared to the concurrent measures, these findings provide support for the internal consistency and construct validity of the GPQ in a sample of patients with low back and upper extremity pain.

Interestingly, but not unexpectedly, the findings of the present study demonstrated a nonlinear, U-shaped association between the GPQ pain-avoidance subscale and pain and disability. In line with a motivational perspective [24,56] stronger endorsement of either pain-avoidance goals or achievement goals was related to greater pain and disability while controlling for gender, age, pain duration, education, and pain catastrophizing. However, for pain severity, this relationship was only found for patients high on negative affect, but not for patients low on negative affect. This latter finding provides support for an affective-motivational perspective postulating that negative affect moderates the relationship between goal pursuit and pain $[35,64]$. For disability, higher negative affectivity in general was associated with higher disability levels independent of the effect of goal pursuit. These findings support the conjecture that pain is experienced in a context of goal pursuit, and that strong endorsement of goals, either avoidance or approach-related goals, is associated with higher disability and pain levels in patients with pain, particularly in those with high negative affect.

Although it was not tested in the present study, a possible explanation for the observed relationship among goal pursuit, pain, and disability is that this relationship is mediated by task persistence. Theories on goal pursuit [27] postulate that achievement goals, as compared to hedonic goals (eg, pain-avoidance goals), elicit task persistence, and that this effect is most pronounced in individuals with high negative affect [34]. Negative affect may inform patients in an achievement context that not enough progress has been made, leading to persistence behavior, whereas negative affect may inform patients in a hedonic context that tasks are no longer enjoyable, leading to avoidance behavior [35]. In turn, increased task persistence or avoidance may eventually lead to increased levels of disability and pain [64]. In line with this hypothesis, it has been shown that high achievement standards increase task persistence in healthy individuals $[4,27]$ and patients 


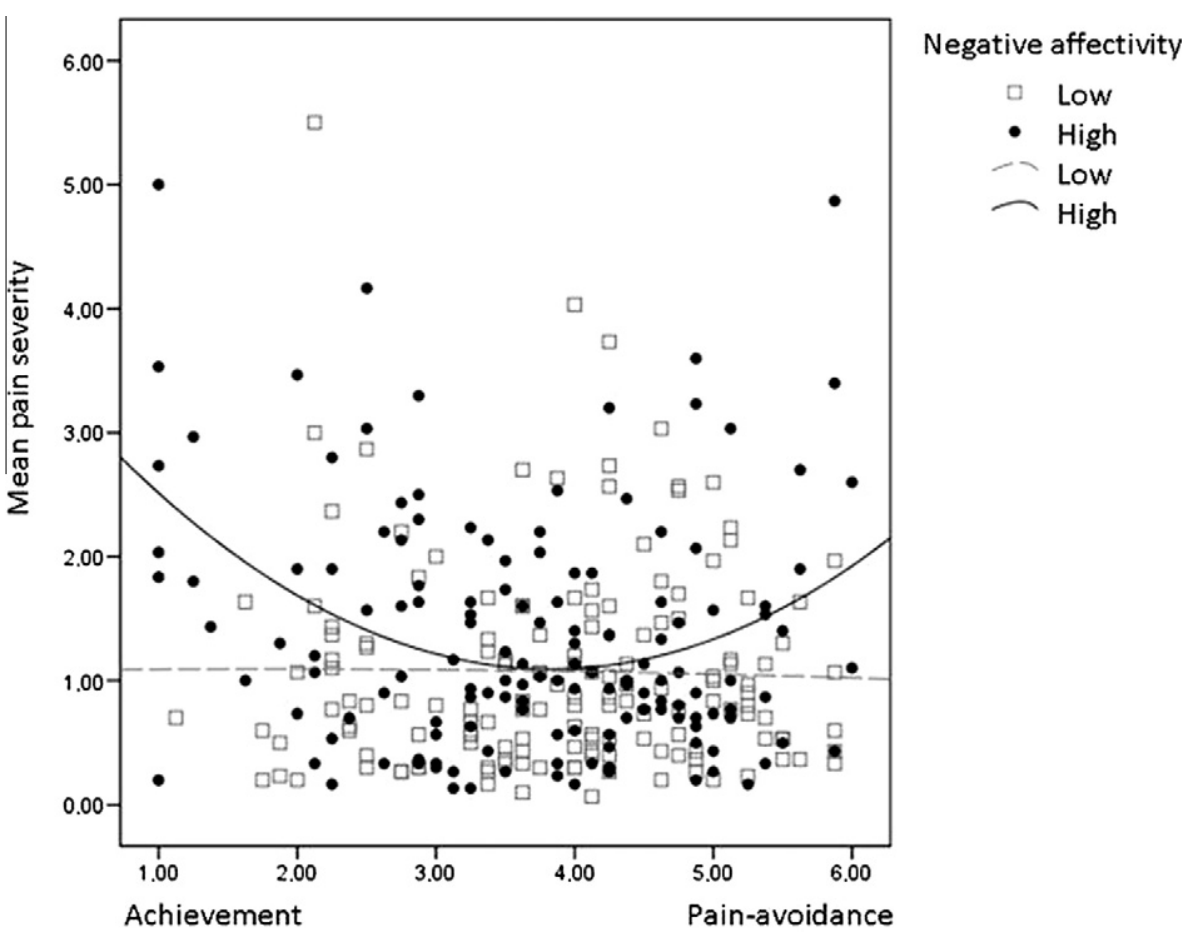

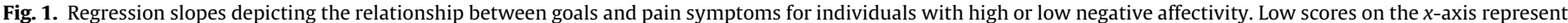
stronger achievement goals, and high scores represent stronger pain-avoidance goals.

with chronic pain [24], particularly in those with high negative affect $[10-12,30,31,34,35,41-43,49,50,65]$. Moreover, it has been shown that excessive avoidance and persistence behavior are associated with increased levels of pain and disability [2,5,21, $23,32,52,59,63]$. However, to our knowledge, it has never been tested whether the observed relationship between goal pursuit and pain, and disability is mediated by the level of task persistence.
Future studies are required testing this mediating relationship. For example, a diary study may be developed exploring the relationship between daily fluctuations in goal pursuit, negative affect, pain, disability, and objective activity levels measured with an accelerometer.

The finding that high negative affect overall was related to higher disability levels is in line with previous research suggesting that

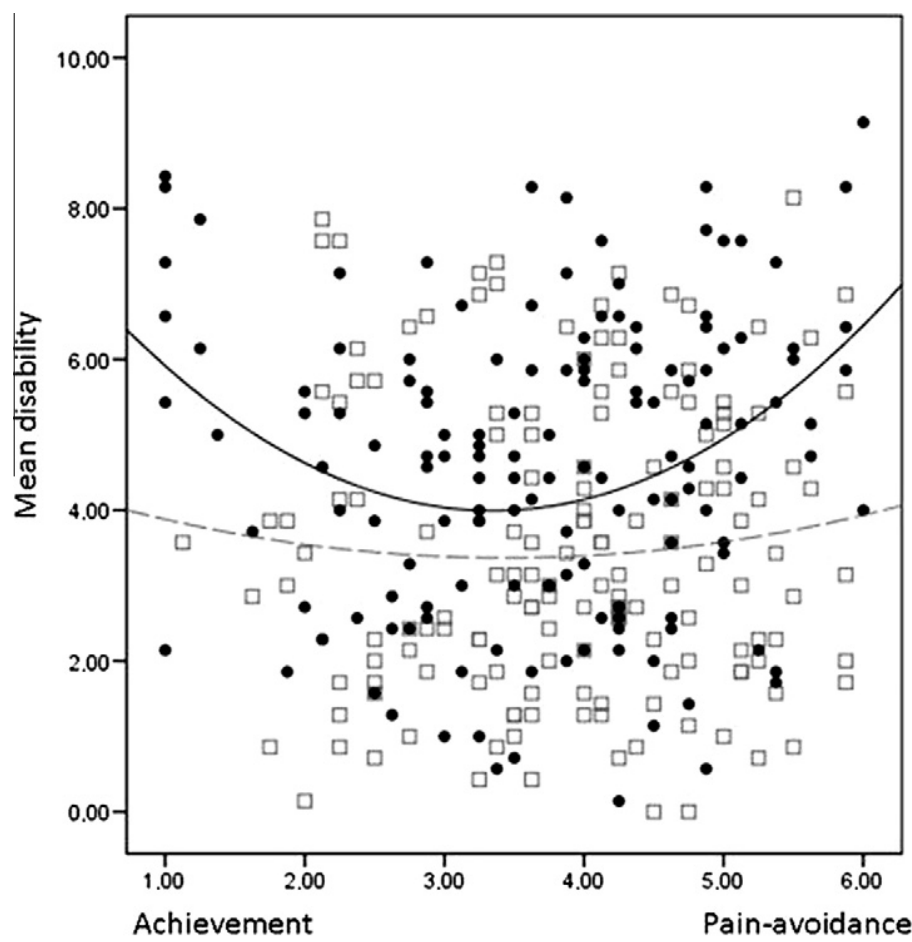

\section{Negative affectivity}

$\square$ Low

- High

Low

$\frown$ High

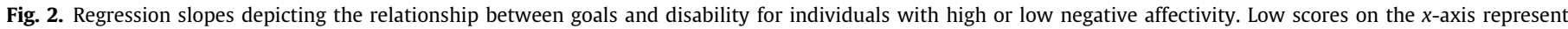
stronger achievement goals, and high scores represent stronger pain-avoidance goals. 
individuals with high negative affect attend to negative aspects of their functioning and interpret and remember their functioning in a negative manner $[38,67]$. On the other hand, it is possible that patients with negative affect show an enhanced tendency to avoid painful physical activities and in turn develop chronic disability [46]. For example, it has been shown that patients with chronic pain show less task persistence on a physical exercise bout when they experience negative as compared to positive moods, independent of the experimentally manipulated goals [24]. Future research is required to unravel the relationship between negative affect and disability in chronic pain.

It is noteworthy that only the pain-related subscale but not the mood-management subscale was related to pain and disability in the present study. This may be because the pain-related subscale is more relevant for pain intensity and pain-related disability. This finding suggests that pain-specific hedonic goals affect pain and disability and not more general hedonic goals, echoing earlier findings showing that responses directly related to the patient's particular pain sensations are more relevant to the understanding of chronic pain than are more general response tendencies [22,33].

A limitation of the study is that the findings are based on correlational data; therefore, it is impossible to draw causal conclusions from the findings. To gain a better understanding of the causal relations between goal pursuit and disability, prospective studies are needed in which habitual goal pursuit is included as a potential predictor for future disability. An additional limitation is that the recruitment of patients through the Internet may have resulted in a selection bias. For example, mean pain duration of the patients was 6 years, and about $23.1 \%$ of the patients experienced pain symptoms of less than 6 months, indicating that specifically patients with chronic pain participated in the study. Future studies may test whether the GPQ predicts pain and disability in patients with acute and chronic pain complaints differentially. Finally, the questionnaire did not comprise items that juxtaposed the 2 hedonic goals, mood-management and pain-avoidance goals. It is possible that both hedonic goals are activated at the same time in some patients. However, according to the MAI model, both goals may have similar effects on behavior dependent on mood, because they are both concerned with maintaining a favourable mood state. For example, a negative mood may lead to task avoidance both in a pain-avoidance and a mood-management-goal context, because in both contexts a negative mood signals that the task is no longer a pleasurable activity. Therefore, items that juxtapose the moodmanagement and pain-avoidance goals were not used in the present study.

Notwithstanding these limitations, the findings of the present study provide evidence for an affective-motivational perspective of chronic pain, postulating that a strong endorsement of either pain-avoidance or achievement goals may adversely affect disability and pain levels, particularly in patients with high negative affect. Patients with a flexible goal pursuit are likely to switch more frequently between both achievement and pain-avoidance goals, depending on the context, and therefore are likely to be less disabled than those who stick with one goal $[17,45]$. Future studies may investigate the potential role of executive functioning, such as task-switching abilities and inhibitory control, in the flexibility of goal pursuit $[37,47]$. The findings of the present study suggest that intervention programs are required targeting negative affect and strong achievement and pain-avoidance goals in patients with pain disorders. Recently, researchers [7] successfully developed a goalpursuit intervention to improve physical capacity in patients with pain. This intervention mainly focused on the strengthening of achievement goals, such as increasing physical fitness, and on the weakening of pain-avoidance goals, such as the prevention of getting injured or reinjured. Because the findings of the present study cautiously suggest that both strong achievement and pain- avoidance goals may be detrimental for the development of chronic pain, these interventions may be extended by including interventions aimed at a more flexible goal pursuit in general.

\section{Conflict of interest statement}

The authors report no conflicts of interest.

\section{Acknowledgments}

This study was supported by an innovation Grant (No. 453-04003 ) provided by the NWO Social Sciences Research Council of The Netherlands. We are most grateful to the colleagues and patients who provided feedback on the preliminary version of the GPQ. We thank Sita van Riet for her assistance throughout the study.

\section{References}

[1] Aldrich S, Eccleston C, Crombez G. Worrying about chronic pain: vigilance to threat and misdirected problem solving. Behav Res Ther 2000;38:457-70.

[2] Andersen JH, Haahr JP, Frost P. Risk factors for more severe regional musculoskeletal symptoms: a two-year prospective study of a general working population. Arthritis Rheum 2007;56:1355-64.

[3] Asmundson GJ, Norton GR, Allerdings MD. Fear and avoidance in dysfunctional chronic back pain patients. Pain 1997;69:231-6.

[4] Bargh JA, Gollwitzer PM, Lee-Chai A, Barndollar K, Trötschel R. The automated will: nonconscious activation and pursuit of behavioral goals. J Pers Soc Psychol 2001;81:1014-27.

[5] Brandt LP, Andersen JH, Lassen CF, Kryger A, Overgaard E, Vilstrup I, Mikkelsen S. Neck and shoulder symptoms and disorders among Danish computer workers. Scand J Work Environ Health 2004;30:399-409.

[6] Carleton NR, McCreary DR, Norton PJ, Asmundson GJG. Brief Fear of Negative Evaluation Scale-Revised. Depress Anxiety 2006;23:243-97.

[7] Christiansen S, Oettingen G, Dahme B, Klinger R. A short goal-pursuit intervention to improve physical capacity: a randomized clinical trial in chronic back pain patients. Pain 2010;149:444-52.

[8] Costa PT, McCrae RR. Revised NEO Personality Inventory (NEO-PI-R) and the Five Factor Inventory (NEO-FFI): professional manual. Odessa, FL: Psychological Assessment Resources Inc; 1992.

[9] Crombez G, Vlaeyen JWS, Heuts PHTG, Lysens R. Pain-related fear is more disabling than pain itself: evidence on the role of pain-related fear in chronic low back pain disability. Pain 1999;80:329-39.

[10] Davey GCL, Eldridge F, Drost J, MacDonald BA. What ends a worry bout? An analysis of changes in mood and stop rule use across the catastrophizing interview task. Behav Res Ther 2007;45:1231-43.

[11] Davey GCL, Startup HM, MacDonald CB, Jenkins D, Patterson K. The use of "as many as can" versus "feel like continuing" stop rules during worrying. Cognit Ther Res 2005;29:155-69.

[12] Davey GCL, Startup HM, Zara A, MacDonald CB, Field AP. The perseveration of checking thoughts and mood-as-input hypothesis. J Behav Ther Exp Psychiatry 2003;34:141-60.

[13] De Vlieger P, Bussche EV, Eccleston C, Crombez G. Finding a solution to the problem of pain: conceptual formulation and the development of the Pain Solutions Questionnaire (PaSol). Pain 2006;123:285-93.

[14] Fishbach A, Labroo AA. Be better or be merry: how mood affects self-control. J Pers Soc Psychol 2007;93:158-73.

[15] Frost RO, Marten P, Lahart C, Rosenblate R. The dimensions of perfectionism. Cognit Ther Res 1990;14:449-68.

[16] Gijsbergs van Wijk C, Kolk AM. Psychometric evaluation of symptom perception related measures. Pers Indiv Dif 1996;20:55-70.

[17] Goossens ME, Kindermans HP, Morley SJ, Roelofs J, Verbunt J, Vlaeyen JW. Selfdiscrepancies in work-related upper extremity pain: relation to emotions and flexible-goal adjustment. Eur J Pain 2010;14:764-70.

[18] Hildebrandt VH, Bongers PM, van Dijk FJH, Kemper HCG, Dul J. Dutch musculoskeletal questionnaire: description and basic qualities. Ergonomics $2001 ; 44: 1038-55$.

[19] Hoekstra HA, Ornel J, De Fruyt F. Manual of the Big Five Personality Inventory: NEO-PI-R and NEO-FFI. Lisse, the Netherlands: Swets Zeitlinger BV; 1996.

[20] Ijzelenberg W, Burdorf A. Risk factors for musculoskeletal symptoms and ensuing health care use and sick leave. Spine 2005;30:1550-6.

[21] Jensen C. Development of neck and hand-wrist symptoms in relation to duration of computer use at work. Scand J Work Environ Health 1993;29:197-205.

[22] Jensen MP, Turner JA, Romano JM, Lawler BK. Relationship of pain-specific beliefs to chronic pain adjustment. Pain 1994;57:301-9.

[23] Juul-Kristensen B, Jensen C. Self-reported workplace related ergonomic conditions as prognostic factors for musculoskeletal symptoms: the "BIT" follow up study on office workers. Occup Environ Med 2005;62:188-94.

[24] Karsdorp PA, Nijst SE, Goossens MEJB, Vlaeyen JWS. The role of current mood and stop rules on physical task performance: an experimental investigation 
in patients with work-related upper extremity pain. Eur J Pain 2010;14:434-40.

[25] Krijns PW, Gaillard AWK, Van Heck GL, Brunia CHM. Personality effects on brain potentials in an S1ss2 paradigm. Pers Indiv Dif 1994;16:561-70.

[26] Kuorinka I, Jonsson B, Kilbom A, Vinterberg H, Biering-Sorensen F, Andersson G, Jorgensen K. Standardised Nordic questionnaires for the analysis of musculoskeletal symptoms. Appl Ergon 1987;18:223-37.

[27] Locke EA, Latham GP. A theory of goal setting and performance. Englewood Cliffs, NJ: Prentice Hall; 1990.

[28] Lousberg R, Van Groenman B, Schmidt AJ, Arntz A, Winter FA. Psychometric properties of the multidimensional Pain Inventory Dutch Language Version (MPI-DLV). Behav Res Ther 1999;37:167-82.

[29] Luime JJ, Koes BW, Miedem HS, Verhaar JAN, Burdorf A. High incidence and recurrence of shoulder and neck pain in nursing home employees was demonstrated during a 2-year follow-up. J Clin Epidemiol 2005;58:407-13.

[30] MacDonald B, Davey GCL. Inflated responsibility and perseverative checking: the effect of negative mood. J Abnorm Psychol 2005;1:176-82.

[31] MacDonald B, Davey GCL. A mood-as-input account of perseverative checking: the relationship between stop rules mood and confidence in having checked successfully. Behav Res Ther 2005;43:69-91.

[32] Macfarlane GJ, Hunt IM, Silman AJ. Role of mechanical and psychosocial factors in the onset of forearm pain: prospective population based study. BM] 2000;321:1-5.

[33] McCracken LM, Gross RT, Aikens J, Carnrike CL. The assessment of anxiety and fear in persons with chronic pain: a comparison of instruments. Behav Res Ther 1996;34:927-33.

[34] Martin LL, Abend T, Sedikides C, Green JD. How would I feel if. ..? Mood as input to a role fulfilment evaluation process. J Pers Soc Psychol 1997;73:242-53.

[35] Martin LL, Ward W, Achee JW, Wyer RS. Mood as input: people have to interpret the motivational implications of their moods. J Pers Soc Psychol 1993;64:317-26.

[36] Mehlum IS, Kjuus H, Veiersted KB, Wergeland E. Self-reported health problems from the Oslo Health Study. Occup Med 2006;56:371-9.

[37] Oosterman JM, Dijkerman HC, Kessel RPC, Scherder EJA. A unique association between cognitive inhibition and pain sensitivity in healthy participants. Eur J Pain 2010;14:1046-50.

[38] Pennebaker JW. The psychology of physical symptoms. New York: SpringerVerlag; 1982

[39] Pleva J, Wade TD. An investigation of the relationship between responsibility and attention deficits characteristic of obsessive-compulsive phenomena. Behav Cogn Psychother 2002;30:399-414.

[40] Pollard CA. Preliminary validity study of the Pain Disability Index. Percept Mot Skills 1984:59:974.

[41] Salkovskis PM, Wroe AL, Gledhill N, Morrison E, Forrester E, Richards C, Reynolds M, Thorpe S. Responsibility attitudes and interpretations are characteristic of obsessive compulsive disorder. Behav Res Ther 2000;38:347-72.

[42] Sanna LJ, Parks CD, Chang EC. Mixed-motive conflict in social dilemmas: mood as input to competitive and cooperative goals. Group Dyn 2003;7:26-40.

[43] Sanna LJ, Meier S, Wegner EA. Counterfactuals and motivation: mood as input to affective enjoyment and preparation. Br J Soc Psychol 2001;40:235-56.

[44] Schafer JL. NORM: multiple imputations of incomplete multivariate data under a normal model. University Park: Pennsylvania State University Department of Statistics; 1999.

[45] Schmitz U, Saile H, Nilges P. Coping with chronic pain: flexible goal adjustment as an interactive buffer against pain-related distress. Pain 1996;67:41-51.
46] Sieben JM, Vlaeyen JW, Portegijs PJ, Verbunt JA, van Riet-Rutgers S, Kester AD, Von Korff M, Arntz A Andre Knottnerus J. A longitudinal study on the predictive validity of the fear-avoidance model in low back pain. Pain 2005;117:162-70.

[47] Solberg Nes L, Roach AR, Segerstrom SC. Executive functions self-regulation and chronic pain: a review. Ann Behav Med 2009;37:173-83.

[48] Staal E, Neinhuijs SW, Keemers-Gels ME, Rosman C, Strobbe LJA. The impact of pain on daily activities following open mesh inguinal hernia repair. Hernia 2007; $12: 153-7$.

[49] Startup HM, Davey GCL. Inflated responsibility and the use of stop rules for catastrophic worrying. Behav Res Ther 2003;41:495-503.

[50] Startup HM, Davey GCL. Mood as input and catastrophic worrying. J Abnorm Psychol 2001;110:83-96.

[51] Sullivan MLJ, Bishop SR, Pivik J. The Pain Catastrophizing Scale: development and validation. Psychol Assess 1995;4:524-32.

[52] Szeto GPY, Straker LM, O'Sullivan PB. A comparison of symptomatic and asymptomatic office workers performing monotonous keyboard work-2. Neck and shoulder kinematics. Man Ther 2005;10:281-91.

[53] Tabachnick BG, Fidell LS. Using multivariate statistics. 5th ed. Boston: Allyn and Bacon; 2007.

[54] Tait RC, Chibnall JT, Krause S. The Pain Disability Index: psychometric properties. Pain 1990;40:171-82.

[55] Trinkoff AM, Lipscomb JA, Geiger-Brown J, Brady B. Musculoskeletal problems of the neck shoulder and back and functional consequences in nurses. Am J Ind Med 2002;41:170-8.

[56] Van Damme S, Crombez G, Eccleston C. Coping with pain: a motivational perspective. Pain 2008;139:1-4.

[57] Van Damme S, Crombez G, Vlaeyen JWS, Goubert L, Van den Broeck A, Van Houdenhove B. De Pain Catastrophizing Scale: psychometrische karakteristieken en normering. Gedragsther 2000;33:209-20.

[58] Van Damme S, Crombez G, Bijttebier P, Goubert L, Van Houdenhove BA Confirmatory factor analysis of the Pain Catastrophizing Scale: invariant factor structure across clinical and non-clinical populations. Pain 2002;96:319-24.

[59] Van den Heuvel SG, van der Beek AJ, Blatter BM, Bongers PM. Do work-related physical factors predict neck and upper limb symptoms in office workers? Int Arch Occup Environ Health 2006;79:585-92.

[60] Van Eijsden-Besseling MDF, Peeters FPML, Reijnen JAW, de Bie RA Perfectionism and coping strategies as risk factors for the development of non-specific work-related upper limb disorder (WRULD). Occup Med 2004;54:122-7.

[61] Vancleef LM, Peters ML, Roelofs J, Asmundson GJ. Do fundamental fears differentially contribute to pain-related fear and pain catastrophizing? An evaluation of the sensitivity index. Eur J Pain 2006;10:527-36.

[62] Vlaeyen JW, Geurts SM, Kole-Snijders AM, Schuerman JA, Groenman NH, van Eek H. What do chronic pain patients think of their pain? Towards a pain cognition questionnaire. Br J Clin Psychol 1990;29:383-94.

[63] Vlaeyen JWS, Linton SJ. Fear-avoidance and its consequences in chronic musculoskeletal pain: a state of the art. Pain 2000;85:317-32.

[64] Vlaeyen JWS, Morley S. Active despite pain: the putative role of stop-rules and current mood. Pain 2004;110:512-6.

[65] Watkins E, Mason A. Mood as input and rumination. Pers Indiv Dif 2002;32:577-87.

[66] Watson D, Clark LA, Tellegen A. Development and validation of brief measures of positive and negative affect: the PANAS scales. J Pers Soc Psychol 1988:54:1063-70

[67] Watson D, Pennebaker JW. Health complaints stress and distress: exploring the central role of negative affectivity. Psychol Rev 1989;96:234-54. 